\title{
DESIGN AND CALCULATION OF PLANETARY TRANSMISSION WITH BEVEL GEARS
}

\author{
Ivan SABO, Milan KLJAJIN, Mirko KARAKAŠIĆ, Željko IVANDIĆ
}

\begin{abstract}
In this paper, the design and calculation of planetary transmission with bevel gears for road vehicles is presented. It must transfer power to the wheels with the possibility that wheels can rotate at different speeds. The basic calculation of transmission is performed for the drive machine, where an internal combustion engine is chosen, and for the driven machine, which is a car, all forces of resistance are calculated so that the transmission needs to be overcome to move the car. Based on the standard ISO $23509: 2016$ norm, the calculation of geometry is performed for the input gear pair and it is defined as a hypoid gear pair. For the planetary transmission, a calculation of gear module for bevel gears is first performed, and after that, the geometry is calculated. The calculation of the stress for root stress and Hertz contact pressure is performed for all bevel gears in transmission.
\end{abstract}

Keywords: bevel gears; design process; planetary transmission

\section{INTRODUCTION}

At the appearance of the first four-wheeled road vehicles, there was a problem of power transmission from the drive machine to the wheels [1]. When a vehicle is moving over a curved path, the outside wheel must cross more distance at the same time as the inner wheel. If both wheels were connected to the same shaft, one or the other would have to slip. Initially, only one wheel would drive, resulting in a series of disadvantages when transmitting. For this reason, transmissions that transmit power to both wheels appear. They ensure that the wheels rotate at different speeds. The technical solution of this problem is based on the differential planetary transmission with the bevel gears. Differential transmission is characterized by transmissions with one input shaft and multiple output shafts. In this case, it is characterized by with two output shafts, because the power needs to transfer on both wheels. Different wheel rotation speeds provide a planetary transmission [2] that consists of sun and planetary bevel gears. When the vehicle is moving straight, the satellites rotate around the axis of the sun bevel gears. However, when the vehicle is moving on the curved path, then the satellites rotate around the axis of the sun bevel gears and around its axis. In this way, one wheel will rotate if the other wheel is completely blocked.

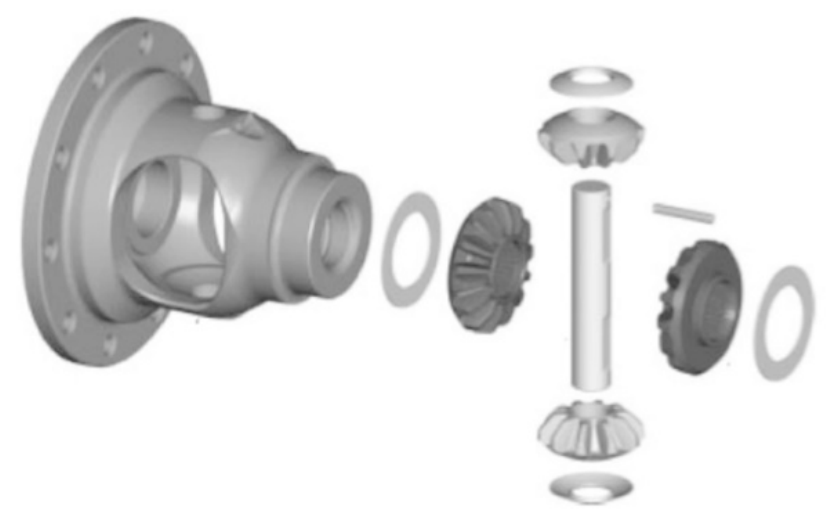

Figure 1 Open differential [3]
Planetary transmissions with bevel gears can be open and with a limited slip. Differentials with a limited slip can be active and passive.

The open differential has a large opening on the supporter that serves for an easier assembly of the bevel gears (Fig. 1). Using the bolt joint, a driven bevel gear is connected on the supporter flange. This gear is a member of the input gear pair.

Limited slip differentials contain additional machine elements that enable the directioning of the torque to the desired wheel. Active transmissions contain electronic feedback systems, while passive transmissions are fully mechanical. Passive transmissions enable the directioning of the torque from the wheel that rotates faster on a slower rotate wheel (Fig. 2).

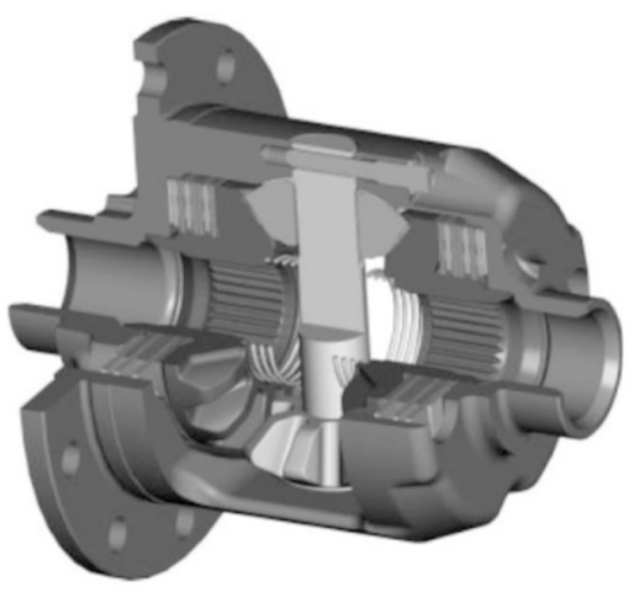

Figure 2 Limited slip differential [3]

Active differentials can direct the torque to any wheel. The basis of the construction is an open differential that has an extra planetary transmission at the output.

The greatest disadvantage of the open differential of a planetary transmission for road vehicles is the inability to direct the torque to the wheel with better adhesion on the 
ground. This problem can be explained when the wheels are on surfaces with different friction factors. The rotation moment at the open differential divides equally to the left and right wheel; however, this is not enough to achieve the traction force on the wheel with better adhesion to drive the vehicle. If it is assumed that one wheel is immobile, then the second wheel rotates twice in relation to the supporter. This means that the wheel that has better adhesion on the ground does not gain power from the drive machine because all power is transmitting on the side with less resistance. This disadvantage reduces the traction force of the vehicle. The problem is possible to solve by blocking the transmission of the differential or by increasing the adhesive force on the wheel on the slippery surface.

\section{BASIC CALCULATION OF TRANSMISSION}

At the beginning, the design of the differential includes a basic calculation. This calculation is important for the determination of the transmission ratio. It is therefore necessary to take into account the data of the drive and the driven machine. The drive machine is an internal combustion engine. The driven machine is a car which includes all forces of resistance important for the calculation of the planetary transmission.

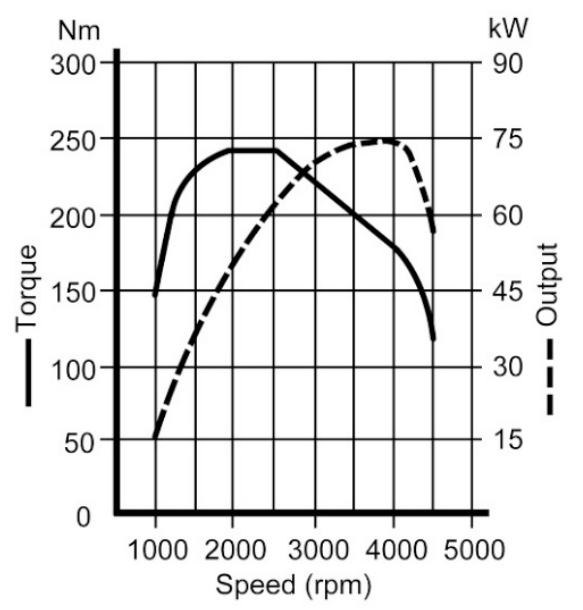

Figure 3 Factory characteristics of the power and torque on the drive machine [4]

Requirements for the calculation and design of the planetary transmission with bevel gears are derived from the requirement list [5]. Following the requirements that are necessary for calculation: the drive machine is an internal combustion engine Volkswagen 1,9 R4 TDI PD with the following technical data [4]: $P_{\mathrm{m}}=74 \mathrm{~kW}$ at speed $n=4000$ $1 / \mathrm{min}, T_{\mathrm{m}}=240 \mathrm{Nm}$ at speed $n=1800-24001 / \mathrm{min}$. The data are graphically presented in the diagram (Fig. 3). Other data are: usability of the gearbox $\eta_{\mathrm{m}}=0.96$, usability of the cardan shaft $\eta_{\mathrm{k}}=0.98$, usability of the differential $\eta_{\mathrm{d}}=0.97$, acceleration of the vehicle $\mathrm{a}_{\mathrm{v}}=2.5 \mathrm{~m} / \mathrm{s}^{2}$, maximum vehicle speed at the highest transmission ratio $v_{\max }=180 \mathrm{~km} / \mathrm{h}$, the vehicle must accelerate from 0 to $100 \mathrm{~km} / \mathrm{h}$ for 11 seconds, the vehicle mass with the passengers and luggage is $m_{\mathrm{v}}=$ $2100 \mathrm{~kg}$, resisting the rise resistance force from $6^{\circ}$, differential dimensions $l \times w \times h=610 \times 400 \times 350 \mathrm{~mm}$, the elements for the transfer of power and motion must be bevel gears, the wheel dimensions are 205/55 16, traction force on the drive wheels must be less than the friction force between the wheels and the ground (no slip) and gearbox transmission ratios: $i_{1}=3.5, i_{2}=2.1, i_{3}=1.32, i_{4}=0.97, i_{5}=0.76, i_{\mathrm{R}}=$ 3.55 .

\subsection{Transmission Load from the Drive Side}

When dimensioning design elements, it is necessary to take the maximum load of the drive machine by which the transmission can be loaded [6]. According to the requirement list, for the drive machine for the transmission, the Volkswagen 1.9 R4 TDI PD engine was selected [5]. The technical data for this engine are listed in the previous title and Fig. 3.

\subsection{Transmission Load from the Driven Side}

The total resistance force of the driven machine is equal to the sum of the rolling resistance force $\left(F_{\mathrm{K}}\right)$, rising resistance force $\left(F_{\mathrm{P}}\right)$ and inertial force of the vehicle $\left(F_{\mathrm{IN}}\right)$. For this calculation, the force of air resistance has been neglected. This is because the geometry of the car design is not defined.

The rolling resistance force is generated because of the deformation of the tire at the point of contact with the ground. It is assumed that the vehicle is running on a flat surface without rising. The rolling resistance is then the greatest. The rolling resistance factor for rolling on the asphalt is $f_{\mathrm{K}}=0.02$. The weight of the vehicle is:

$G_{\mathrm{V}}=m_{\mathrm{V}} \cdot g=2100 \cdot 9.81=20601 \mathrm{~N}$

The rolling resistance force is:

$F_{\mathrm{K}}=f_{\mathrm{K}} \cdot G_{\mathrm{V}}=0.02 \cdot 20601=412.02 \mathrm{~N}$

The rising resistance force is a component of the weight force vector that acts in the opposite direction to the motion of the rising vehicle (Fig. 4). The largest rising angle for road vehicles is $\gamma=6^{\circ}$.

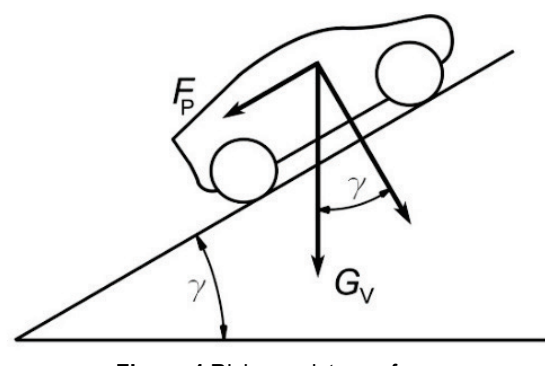

Figure 4 Rising resistance force

The rising resistance force is:

$F_{\mathrm{P}}=G_{\mathrm{V}} \cdot \sin \gamma=20601 \cdot \sin 6^{\circ}=2153.391 \mathrm{~N}$ 
The vehicle's inertial force occurs when the vehicle is accelerating. It is necessary then the vehicle accelerate translational. It is also necessary to accelerate all rotating elements. The contribution factor of rotating masses for the first degree of transmission is $\psi=1.165$. Hence, the vehicle's inertial force is:

$$
F_{\text {IN }}=m_{\mathrm{V}} \cdot a \cdot \psi=2100 \cdot 2.5 \cdot 1.165=6116.25 \mathrm{~N}
$$

The total resistance force of the driven machine is:

$$
F_{\mathrm{W}}=F_{\mathrm{K}}+F_{\mathrm{P}}+F_{\mathrm{IN}}=8681.661 \mathrm{~N}
$$

\subsection{Calculation of the Transmission Ratio}

The scheme of the planetary transmission with bevel gears, derived from the requirement list, is presented in Fig. 5.

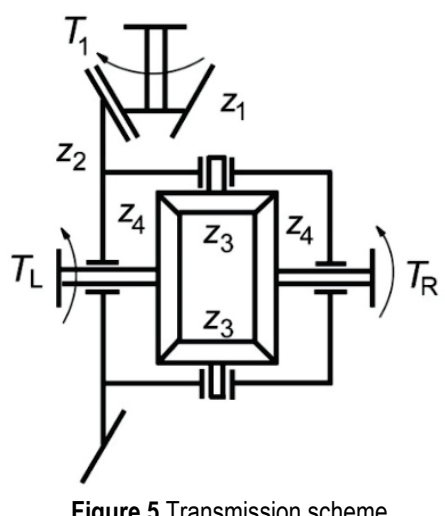

For calculating the transmission ratio from the diagram (Fig. 3) for the torque value $T_{\mathrm{m}}=240 \mathrm{~N} \cdot \mathrm{m}$, the read value of the drive machine number of revolutions is $n=1800 \mathrm{l} / \mathrm{min}$. Machine power is then $P_{\mathrm{m}}=45.24 \mathrm{~kW}$. The power at the entrance to the planetary transmission is:

$P_{1}=P_{\mathrm{m}} \cdot \eta_{\mathrm{m}} \cdot \eta_{\mathrm{k}}=45.24 \cdot 0.96 \cdot 0.98=42,561 \mathrm{~kW}$

The angular speed on the first degree of the gearbox transmission is:

$\omega_{1}=\frac{\omega_{\mathrm{m}}}{i_{1}}=\frac{188.4956}{3.5}=53.8559 \mathrm{rad} / \mathrm{s}$

The torque that is transmitting via the cardan shaft to the bevel gear $z_{1}$ (Fig. 5) is:

$T_{1}=\frac{P_{1}}{\omega_{1}}=\frac{42.561 \times 10^{3}}{53.8559}=790.276 \mathrm{~N} \cdot \mathrm{m}$ speed:

$$
\frac{\omega_{\mathrm{L}}-\omega_{2}}{\omega_{\mathrm{R}}-\omega_{2}}=-\frac{z_{\mathrm{R}}}{z_{\mathrm{L}}}=-1
$$

The drive is transmitting via the cardan shaft to the rear wheels of the vehicle. It is assumed that the centre of gravity of the vehicle is at its middle. The centre of gravity is equally far from the front and rear wheels. The distance between the axles of the vehicle is $2700 \mathrm{~mm}$. Therefore, the force on one of the last two wheels of the vehicle equals a quarter of the weight of the vehicle. The amount of this force is $F_{\mathrm{a}}=$ $5150.25 \mathrm{~N}$. The friction factor for contact between the tire and surface, in the case of tire-dry asphalt, is $\mu=0.9$, so the friction force on one wheel equals:

$$
F_{\mathrm{f}}=\mu \cdot F_{\mathrm{a}}=0,9 \cdot 5150.25=4635.225 \mathrm{~N}
$$

The traction force must be greater than the total resistance force. It must also be smaller than the friction force to avoid slipping. The greatest traction force is:

$$
F_{\mathrm{TR}}=2 \cdot F_{\mathrm{f}}=2 \cdot 4635.225=9270.45 \mathrm{~N}
$$

Since the planetary transmission is derived as the open differential, the torque is equally divided into the left and right wheel:

$T_{\mathrm{L}}=T_{\mathrm{R}}=F_{\mathrm{f}} \cdot r_{\mathrm{d}}=4635.225 \cdot 0.25=1160.66 \mathrm{~N} \cdot \mathrm{m}$

The torque on a large wheel gear $z_{2}$, assumed that there are no losses, is:

$T_{2}=T_{\mathrm{L}}+T_{\mathrm{R}}=1160.66+1160.66=2321.32 \mathrm{~N} \cdot \mathrm{m}$

The transmission ratio of bevel gears $z_{1}$ and $z_{2}$ is:

$u=\frac{T_{2}}{T_{1}}=\frac{2321.32}{790.276}=2.937 \approx 3$

Because of the losses, which are not considered, $u=3$. The following is the control calculation with losses:

$$
\begin{aligned}
& \omega_{2}=\frac{\omega_{1}}{u}=\frac{53.8559}{3}=17.95197 \mathrm{rad} / \mathrm{s} \\
& P_{2}=P_{1} \cdot \eta_{\mathrm{d}}=42.561 \cdot 0.97=41.284 \mathrm{~kW} \\
& \begin{array}{l}
T_{2}=\frac{P_{2}}{\omega_{2}}=\frac{41.284 \times 10^{3}}{17.95197}=2299.69 \mathrm{~N} \cdot \mathrm{m}<2321.3 \mathrm{~N} \cdot \\
\text { It can be confirmed that the calculation is exact. } \\
3 \text { CALCULATION OF BEVEL GEARS } \\
3.1 \text { Calculation of the Sun and Planetary Bevel Gear }
\end{array}
\end{aligned}
$$

The bevel gear load is done according to the mean values of the additional gears as the load of virtual gears. The 
calculation is the same as the calculation of the gears, only that the intermediate additional gear has the same width as the bevel gear [7]. The bevel gear teeth number are $z_{3}=12$ and $z_{4}=16$. Therefore, the kinematic ratio is $u=1.33$. The angle between the axes of the bevel gears is $\Sigma=90^{\circ}$. The angles of the pitch bevel gears are:

$$
\begin{aligned}
& \tan \delta_{3}=\frac{z_{3}}{z_{4}}=\frac{12}{16}=0,75 \rightarrow \delta_{3}=36.8699^{\circ} \\
& \delta_{4}=\Sigma-\delta_{3}=90^{\circ}-36.8699^{\circ}=53.1301^{\circ}
\end{aligned}
$$

Orientation calculations of the module were performed. The module considering the load of the tooth root is:

$$
\begin{aligned}
& m \geq 2 \cdot \sqrt[3]{\frac{T_{\max } \cdot \cos \delta_{3}}{z_{3} \cdot \lambda \cdot \sigma_{\mathrm{FP} 3}} \cdot Y_{\mathrm{F}}}= \\
& =2 \cdot \sqrt[3]{\frac{1.16 \times 10^{6} \cdot \cos 36.8699^{\circ}}{12 \cdot 22 \cdot 333.3333} \cdot 2.2}=5.69 \mathrm{~mm}
\end{aligned}
$$

The module considering the load of the tooth flank is:

$$
\begin{aligned}
& m \geq 2 \cdot \sqrt[3]{\frac{u_{\mathrm{V}}+1}{u_{\mathrm{V}}} \cdot \frac{T_{\max } \cdot \cos ^{2} \delta_{3}}{z_{3}^{2} \cdot \lambda \cdot \sigma_{\mathrm{HP} 3}^{2}} \cdot Z_{\mathrm{M}}^{2} \cdot Z_{\mathrm{HV}}^{2} \cdot Z_{\varepsilon \mathrm{V}}^{2}}= \\
& =2 \cdot \sqrt[3]{\frac{1.77+1}{1.77} \cdot \frac{1.16 \times 10^{6} \cdot \cos ^{2} 36.87^{\circ}}{12^{2} \cdot 22 \cdot 1304} \cdot 190^{2} \cdot 2.5^{2}}= \\
& =5.96 \mathrm{~mm}
\end{aligned}
$$

The adopted module of bevel gears is $m=6 \mathrm{~mm}$.

\subsubsection{Dimensions of the Planetary Bevel Gear}

The dimensions are defined with the help of calculations and they determine the geometry of the planetary bevel gear $z_{3}$.

Pitch diameter:

$$
d_{3}=z_{3} \cdot m=12 \cdot 6=72 \mathrm{~mm}
$$

Radius of gear rack:

$$
R_{\mathrm{a}}=\frac{d_{3}}{2 \cdot \sin \delta_{3}}=\frac{72}{2 \cdot \sin 36.8699^{\circ}}=60 \mathrm{~mm}
$$

Face width:

$$
b=\frac{R_{\mathrm{a}}}{3}=\frac{60}{3}=20 \mathrm{~mm}
$$

Middle pitch diameter of the bevel gear:

$$
d_{\mathrm{m} 3}=d_{3}-b \cdot \sin \delta_{3}=72-20 \cdot \sin 36.87^{\circ}=60 \mathrm{~mm}
$$

Teeth number of the equivalent gear:

$$
z_{\mathrm{v} 3}=\frac{z_{3}}{\cos \delta_{3}}=\frac{12}{\cos 36.8699^{\circ}}=15
$$

Middle module of the bevel gear:

$$
m_{\mathrm{m}}=\frac{d_{\mathrm{m} 3}}{z_{3}}=\frac{60}{12}=5 \mathrm{~mm}
$$

Clearance:

$c=0.25 \cdot m=0.25 \cdot 6=1.5 \mathrm{~mm}$

Whole depth:

$h_{3}=h_{4}=2 \cdot m+c=2 \cdot 6+1.5=13.5 \mathrm{~mm}$

Addendum depth for the zero pair of bevel gears:

$h_{\mathrm{a} 3}=h_{\mathrm{a} 4}=m=6 \mathrm{~mm}$

Dedendum depth for the zero pair of bevel gears:

$h_{\mathrm{f} 3}=h_{\mathrm{f} 4}=m+c=6+1.5=7.5 \mathrm{~mm}$

Addendum circle diameter:

$d_{\mathrm{a} 3}=d_{3}+2 \cdot h_{\mathrm{a} 3} \cdot \cos \delta_{3}=$

$72+2 \cdot 6 \cdot \cos 36.8699^{\circ}=81.6 \mathrm{~mm}$

Teeth face angle:

$\tan \kappa_{\mathrm{a} 3}=\frac{h_{\mathrm{a} 3}}{R_{\mathrm{a}}}=\frac{6}{60}=0.1 \rightarrow \kappa_{\mathrm{a} 3}=\kappa_{\mathrm{a} 4}=5.7106^{\circ}$

Teeth root angle:

$\tan \kappa_{\mathrm{f} 3}=\frac{h_{\mathrm{f} 3}}{R_{\mathrm{a}}}=\frac{7.5}{60}=0.125 \rightarrow \kappa_{\mathrm{f} 3}=\kappa_{\mathrm{f} 4}=7.125016^{\circ}$

Face angle of the bevel gear:

$\delta_{\mathrm{a} 3}=\delta_{3}+\kappa_{\mathrm{a} 3}=36.8699^{\circ}+5.7106^{\circ}=42.5805^{\circ}$

Inner addendum diameter of the tooth:

$d_{\mathrm{ia} 3}=d_{\mathrm{a} 3}-2 \cdot \frac{b \cdot \sin \delta_{\mathrm{a} 3}}{\cos \kappa_{\mathrm{a} 3}}=$

$=81.6-2 \cdot \frac{20 \cdot \sin 42.5805^{\circ}}{\cos 5.7106^{\circ}}=54.4 \mathrm{~mm}$ 
Pitch diameter of the middle equivalent gear:

$d_{\mathrm{vm} 3}=\frac{d_{\mathrm{m} 3}}{\cos \delta_{3}}=\frac{60}{\cos 36.8699^{\circ}}=75 \mathrm{~mm}$

Pitch diameter of the equivalent gear:

$d_{\mathrm{v} 3}=\frac{d_{3}}{\cos \delta_{3}}=\frac{72}{\cos 36.8699^{\circ}}=90 \mathrm{~mm}$

Addendum diameter of the equivalent gear:

$d_{\mathrm{va} 3}=d_{\mathrm{v} 3}+2 \cdot h_{\mathrm{a} 3}=90+2 \cdot 6=102 \mathrm{~mm}$

Base diameter of the equivalent gear:

$d_{\mathrm{vb} 3}=d_{\mathrm{v} 3} \cdot \cos \alpha=90 \cdot \cos 20^{\circ}=84.5723 \mathrm{~mm}$

\subsubsection{Dimensions of the Sun Bevel Gear}

Dimensions that define the geometry of the sun bevel gear $z_{4}$ are determined by expressions that are equivalent to the expressions for determining the dimensions of the bevel gear $z_{3}$. It is only necessary to use the members with the index note for the bevel gear $z_{4}$. The dimensions of the bevel gear $z_{4}$ are presented in Tab. 1.

Table 1 Dimensions of the bevel gear $z_{4}$

\begin{tabular}{|l|c|c|}
\hline \multicolumn{1}{|c|}{ Name } & Mark & Amount \\
\hline Pitch diameter & $d_{4}$ & $96 \mathrm{~mm}$ \\
\hline Middle pitch diameter & $d_{\mathrm{m} 4}$ & $80 \mathrm{~mm}$ \\
\hline Teeth number of the equivalent gear & $z_{\mathrm{v} 4}$ & $26.6666 \mathrm{~mm}$ \\
\hline Addendum circle diameter & $d_{\mathrm{a} 4}$ & $103.2 \mathrm{~mm}$ \\
\hline Face angle of the bevel gear & $\delta_{\mathrm{a} 4}$ & $58.8407^{\circ}$ \\
\hline Pitch diameter of the middle equivalent gear & $d_{\mathrm{vm} 4}$ & $133.33 \mathrm{~mm}$ \\
\hline Pitch diameter of the equivalent gear & $d_{\mathrm{v} 4}$ & $160 \mathrm{~mm}$ \\
\hline Addendum diameter of the equivalent gear & $d_{\mathrm{va} 4}$ & $172 \mathrm{~mm}$ \\
\hline Base diameter of the equivalent gear & $d_{\mathrm{v} 64}$ & $150.351 \mathrm{~mm}$ \\
\hline
\end{tabular}

\subsubsection{Load Calculation of the Tooth Root on the Planetary and Sun Bevel Gear}

According to the DIN for the material: the steel for cementing, mark $15 \mathrm{CrNi}$, has the perm strength in the tooth root of $\sigma_{\mathrm{Flim} 3}=500 \mathrm{MPa}$. The allowed stress in the tooth root is:

$\sigma_{\mathrm{FP} 3}=\sigma_{\mathrm{FP} 4}=\frac{\sigma_{\mathrm{Flim} 3}}{S_{\mathrm{Flim}}} \cdot \frac{Y_{\mathrm{m}}}{Y_{\mathrm{sa}}} \cdot K_{\mathrm{FX}} \cdot Y_{\mathrm{N}} \cdot Y_{\mathrm{R}}=$

$=\frac{500}{1.5} \cdot \frac{2.1}{1.4} \cdot 1 \cdot 1 \cdot 1.025=512.5 \mathrm{MPa}$

It was beforehand determined that the planetary transmission will contain four planetary bevel gears. According to that, the force on the tooth is:
$F_{\mathrm{tm} 3}=\frac{T_{2}}{4 \cdot d_{\mathrm{m} 3}}=\frac{2.3 \times 10^{6}}{4 \cdot 60}=9583.333 \mathrm{~N}$ is:

The stress into the tooth root of the planetary bevel gear

$$
\begin{aligned}
& \sigma_{\mathrm{F} 3}=\frac{F_{\mathrm{tm} 3}}{b \cdot m_{\mathrm{m}}} \cdot Y_{\mathrm{F}} \cdot Y_{\varepsilon \mathrm{V}} \cdot K_{\mathrm{F} \alpha} \cdot K_{\mathrm{F} \beta}= \\
& =\frac{9583.333}{20 \cdot 5} \cdot 3.25 \cdot 1 \cdot 1 \cdot 1=311.4583 \mathrm{MPa}
\end{aligned}
$$

Since $\sigma_{\mathrm{F} 3}<\sigma_{\mathrm{FP} 3}$, the calculation satisfies.

The stress into the tooth root of the sun bevel gear is $\sigma_{\mathrm{F} 4}$ $=253.9583 \mathrm{MPa}$. Since $\sigma_{\mathrm{F} 4}<\sigma_{\mathrm{FP} 4}$, the calculation satisfies.

\subsubsection{Load Calculation of the Tooth Flank on the Planetary and Sun Bevel Gear}

For the material: steel $15 \mathrm{CrNi}$, which has the perm strength in the tooth flank of $\sigma_{\mathrm{Hlim} 3}=1630 \mathrm{MPa}$, the allowed stress in the tooth flank is:

$$
\begin{aligned}
& \sigma_{\mathrm{HP} 3}=\sigma_{\mathrm{HP} 4}=\frac{\sigma_{\mathrm{Hlim} 3}}{S_{\mathrm{H} \min }} \cdot K_{\mathrm{L}} \cdot K_{\mathrm{HX}} \cdot Z_{\mathrm{R}} \cdot Z_{\mathrm{V}} \cdot Z_{\mathrm{N}} \cdot Z_{\mathrm{W}}= \\
& =\frac{1630}{1.25} \cdot 1.05 \cdot 1 \cdot 1 \cdot 1.025 \cdot 1 \cdot 1.1=1543.773 \mathrm{MPa}
\end{aligned}
$$

The stress on the tooth flank of the planetary bevel gear:

$$
\begin{aligned}
& \sigma_{\mathrm{H} 3}=Z_{\mathrm{M}} \cdot Z_{\mathrm{HV}} \cdot Z_{\varepsilon \mathrm{V}} \cdot \sqrt{\frac{u_{\mathrm{v}}+1}{u_{\mathrm{v}}} \cdot \frac{F_{\mathrm{tm} 3}}{b \cdot d_{\mathrm{vm} 3}} \cdot K_{\mathrm{H} \alpha} \cdot K_{\mathrm{H} \beta}}= \\
& =189.84 \cdot 2.5 \cdot 1 \cdot \sqrt{\frac{1.78+1}{1.78} \cdot \frac{9583.33}{20 \cdot 75} \cdot 1 \cdot 1}= \\
& =1499.1262 \mathrm{MPa}
\end{aligned}
$$

Since $\sigma_{\mathrm{H} 3}<\sigma_{\mathrm{HP} 3}$, the calculation satisfies.

The stress into the tooth flank of sun bevel gear is $\sigma_{\mathrm{H} 4}=$ 1124.6352 MPa. Since $\sigma_{\mathrm{H} 4}<\sigma_{\mathrm{HP} 4}$, the calculation satisfies.

\subsection{Hypoid Gears Calculation}

This calculation is made according to the ISO 23509:2016 norm. In Tab. 2, the geometric values necessary for the calculation are defined.

Table 2 Input geometry values
\begin{tabular}{|l|c|c|}
\hline \multicolumn{1}{|c|}{ Name } & Mark & Amount \\
\hline Shaft angle & $\Sigma$ & $90^{\circ}$ \\
\hline Hypoid offset & $a$ & $50 \mathrm{~mm}$ \\
\hline Number of teeth (pinion) & $z_{1}$ & 14 \\
\hline Number of teeth (wheel) & $z_{2}$ & 42 \\
\hline Outer pitch diameter of wheel & $d_{\mathrm{e} 2}$ & $270 \mathrm{~mm}$ \\
\hline Wheel face width & $b_{2}$ & $40 \mathrm{~mm}$ \\
\hline Mean spiral angle of wheel & $\beta_{\mathrm{m} 2}$ & $35^{\circ}$ \\
\hline Cutter radius & $r_{\mathrm{c} 0}$ & $115 \mathrm{~mm}$ \\
\hline
\end{tabular}


Since the calculation is very extensive, the calculation is made using the Excel spreadsheet calculator (Fig. 6). In This figure is presented only as a part of the calculation. The calculation contains an iteration procedure for the determination of the condition $\left|R_{\mathrm{mint}}-R_{\mathrm{m} 1}\right|<0.0001 \cdot R_{\mathrm{m} 1}$. Before the iteration procedure, it is necessary to determine the next parameters: gear ratio $u=3$, hypoid dimension factor $F=1$, wheel pitch angle $\delta_{2}=62.68^{\circ}$ and pinion pitch angle $\delta_{1}=25.29^{\circ} . R_{\mathrm{m} 1}$ is calculated according to the expression:

$$
R_{\mathrm{m} 1}=\frac{d_{\mathrm{m} 1}}{2 \cdot \sin \delta_{1}}
$$

$R_{\text {mint }}$ is calculated according to:

$$
R_{\text {mint }}=\frac{A_{3} \cdot A_{4}}{A_{5} \cdot A_{6}+A_{3} \cdot A_{7}}
$$

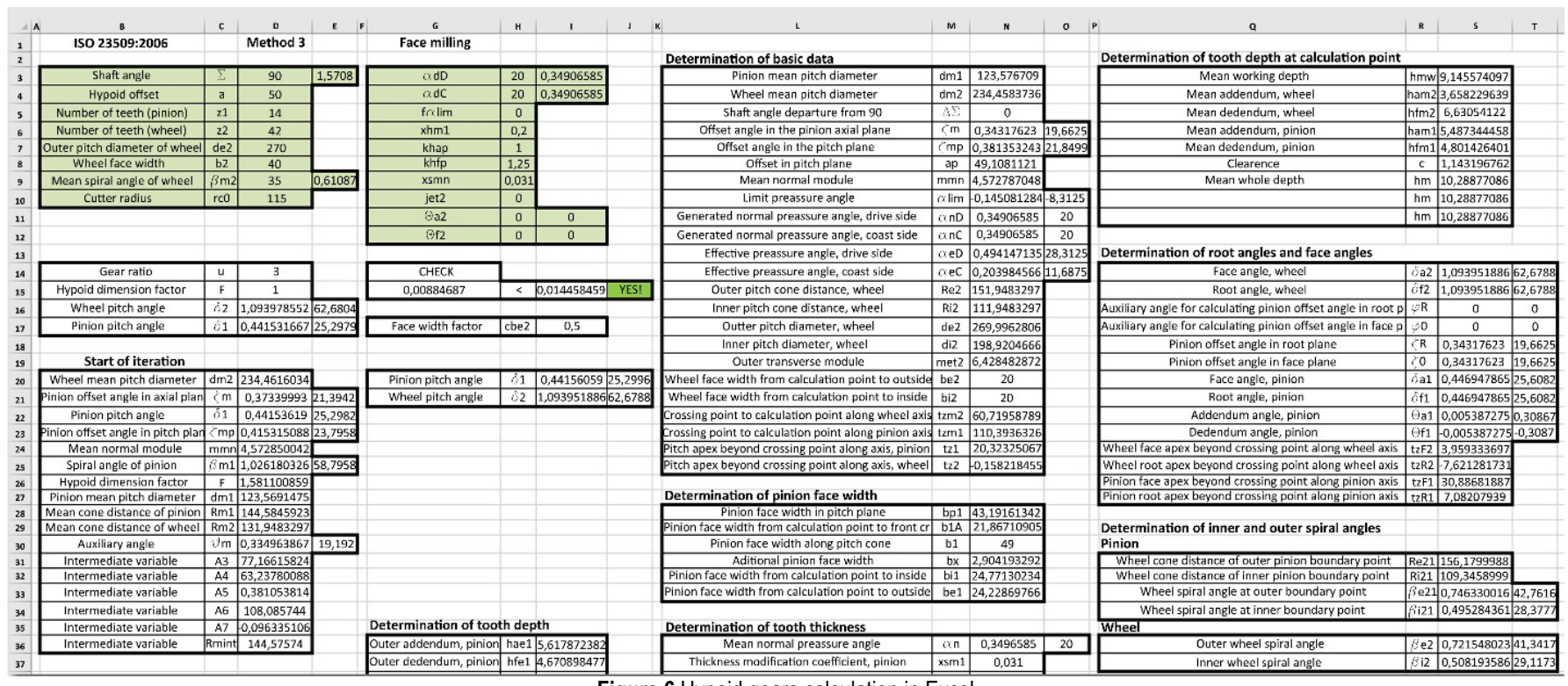

Figure 6 Hypoid gears calculation in Excel

Table 3 Remaining geometric dimensions

\begin{tabular}{|c|c|c|}
\hline Outer pitch cone distance, pinion & Re1 & 168,81329 \\
\hline Inner pitch cone distance, pinion & Ri1 & 119,81329 \\
\hline Outer pitch diameter, pinion & de1 & 144,2850201 \\
\hline Inner pitch diameter, pinion & di1 & 102,4046327 \\
\hline Outside diameter, pinion & dae1 & 154,4430979 \\
\hline Outside diameter, wheel & dae2 & 273,3543739 \\
\hline Outer root diameter, pinion & dfe1 & 135,8392337 \\
\hline Outer root diameter, wheel & dfe2 & 263,9097366 \\
\hline Inner addendum diameter diameter, pinion & dai1 & 112,0853911 \\
\hline Inner addendum diameter diameter, wheel & dai2 & 202,2785598 \\
\hline Inner dedendum diameter diameter, pinion & dfi1 & 93,48152686 \\
\hline Inner dedendum diameter diameter, wheel & dfi2 & 192,8339226 \\
\hline Crossing point to crown along axis, pinion & txo1 & 129,8976525 \\
\hline Crossing point to crown along axis, wheel & txo2 & 66,6490006 \\
\hline Crossing point to front crown along axis, pinion & txi1 & 85,71025773 \\
\hline Crossing point to front crown along axis, wheel & txi2 & 48,28988394 \\
\hline Pinion whole depth, perpendicular to the root cone & ht1 & 10,28877086 \\
\hline
\end{tabular}

Along with the calculation, the Excel spreadsheet contains the next calculation points: calculation of the basic geometric sizes of bevel gears, the mean tooth depth calculation, calculation of the face and root angles, face width calculation of the pinion gear, calculation of the inner and outer spiral angle, calculation of the inner and outer depth of teeth, teeth thickness calculation and calculation of the remaining geometric dimensions. The results of the last calculation point are presented in Tab. 3. The obtained results are expressed in millimetres.

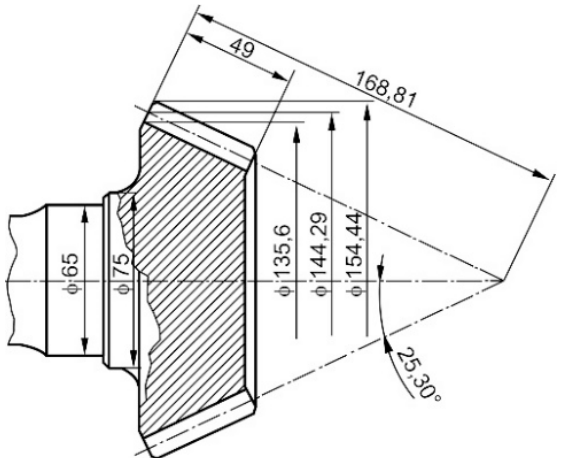

Figure 7 Pinion gear

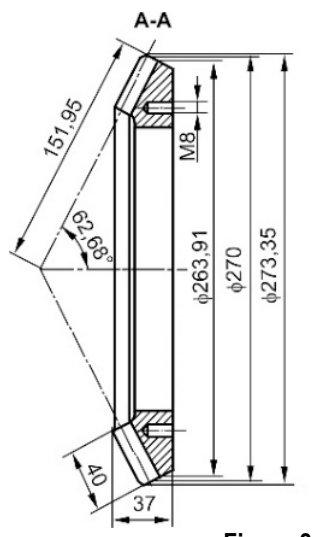

Figure 8 Wheel gear

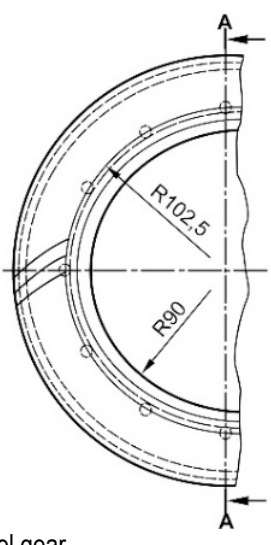


A detailed analytical calculation, with all the necessary expressions, is presented in [5].

According the calculation, the pinion and wheel bevel gear are designed. The dimensions are presented in Fig. 7 and Fig. 8 .

\subsubsection{Load Calculation of the Tooth Root and the Flank of the Pinion Hypoid Gear}

For the material of the pinion sun gear, according to the DIN, the 17CrNiMo6 steel for cementing was selected. The amounts of the perm strength for the tooth root and flank are $\sigma_{\text {Flim } 1}=500 \mathrm{MPa}$ and $\sigma_{\mathrm{Hlim} 1}=1630 \mathrm{MPa}$. The allowed stress on the tooth root is:

$$
\begin{aligned}
& \sigma_{\mathrm{FP} 1}=\frac{\sigma_{\mathrm{Flim} 1}}{S_{\text {Flim }}} \cdot \frac{Y_{\mathrm{m}}}{Y_{\mathrm{sa}}} \cdot K_{\mathrm{FX}} \cdot Y_{\mathrm{N}} \cdot Y_{\mathrm{R}}= \\
& =\frac{500}{1.5} \cdot \frac{2.1}{1.6} \cdot 1 \cdot 1 \cdot 1,025=448.4375 \mathrm{MPa}
\end{aligned}
$$

The force on the tooth is:

$F_{\mathrm{m} t 1}=\frac{2 \cdot T_{1}}{d_{e 1}}=\frac{2 \cdot 790271.8}{144.285}=10954.3168 \mathrm{~N}$

It follows that:

$$
\begin{aligned}
& \sigma_{\mathrm{F} 01}=\frac{F_{\mathrm{mt} 1}}{b_{1} \cdot m_{\mathrm{mn}}} \cdot Y_{\mathrm{Fa}} \cdot Y_{\mathrm{sa}} \cdot Y_{\varepsilon} \cdot Y_{\beta}= \\
& =\frac{10954.316}{49 \cdot 4.572} \cdot 3.25 \cdot 1.6 \cdot 0.364 \cdot 0.75=69.38 \mathrm{MPa}
\end{aligned}
$$

The amount of stress on the tooth root is:

$$
\begin{aligned}
& \sigma_{\mathrm{F} 1}=\sigma_{\mathrm{F} 01} \cdot K_{\mathrm{A}} \cdot K_{\mathrm{V}} \cdot K_{\mathrm{F} \alpha} \cdot K_{\mathrm{F} \beta}= \\
& =69.383 \cdot 1.5 \cdot 1.05 \cdot 1 \cdot 1=109.2184 \mathrm{MPa}
\end{aligned}
$$

Since $\sigma_{\mathrm{F} 1}<\sigma_{\mathrm{FP} 1}$, the calculation satisfies.

The allowed stress on the tooth flank is:

$$
\begin{aligned}
& \sigma_{\mathrm{HP} 1}=\frac{\sigma_{\mathrm{Hlim} 1}}{S_{\mathrm{H} \min }} \cdot K_{\mathrm{L}} \cdot K_{\mathrm{HX}} \cdot Z_{\mathrm{R}} \cdot Z_{\mathrm{V}} \cdot Z_{\mathrm{N}} \cdot Z_{\mathrm{W}}= \\
& =\frac{1630}{1.25} \cdot 1.05 \cdot 1 \cdot 1 \cdot 1.05 \cdot 1 \cdot 1.1=1581.426 \mathrm{MPa}
\end{aligned}
$$

It follows that:

$$
\begin{aligned}
& \sigma_{\mathrm{H} 01}=Z_{\mathrm{H}} \cdot Z_{\mathrm{E}} \cdot Z_{\varepsilon} \cdot Z_{\beta} \cdot Z_{\mathrm{K}} \cdot \sqrt{\frac{F_{\mathrm{tm} 1}}{b_{1} \cdot d_{\mathrm{v} 1}} \cdot \frac{u_{\mathrm{v}}+1}{u_{\mathrm{v}}}}= \\
& =1.79 \cdot 189.8 \cdot 1 \cdot 0.71 \cdot 0.85 \cdot \sqrt{\frac{10954.3}{49 \cdot 159.5} \cdot \frac{5.91+1}{5.91}}= \\
& =266.9 \mathrm{MPa}
\end{aligned}
$$

The amount of stress on the tooth flank is:

$$
\begin{aligned}
& \sigma_{\mathrm{H} 1}=\sigma_{\mathrm{H} 01} \cdot \sqrt{K_{\mathrm{A}} \cdot K_{\mathrm{V}} \cdot K_{\mathrm{H} \alpha} \cdot K_{\mathrm{H} \beta}}= \\
& =266.9106 \cdot \sqrt{1.5 \cdot 1.05 \cdot 1 \cdot 1}=334.9701 \mathrm{MPa}
\end{aligned}
$$

Since $\sigma_{\mathrm{H} 1}<\sigma_{\mathrm{HP} 1}$, the calculation satisfies.

\subsubsection{Load Calculation of the Tooth Root and the Flank of the Wheel Gear}

For the material of the wheel gear, according to the DIN, the $16 \mathrm{MnCr} 5$ steel for cementing was selected. The amounts of the perm strength for the tooth root and the flank are $\sigma_{\text {Flim2 }}$ $=460 \mathrm{MPa}$ and $\sigma_{\mathrm{Hlim} 2}=1630 \mathrm{MPa}$.

According to the Eq. (48), the allowed stress on the tooth root for the wheel gear is $\sigma_{\mathrm{FP} 2}=370.8427 \mathrm{MPa}$. According to the Eq. (49), the force on the tooth is $F_{\mathrm{mt2}}=17037.2705 \mathrm{~N}$. Hence, according to the Eq. (50), it follows that $\sigma_{\mathrm{F} 02}=$ 147.6882 MPa. The stress on the tooth root, according to Eq. $(51)$, is $\sigma_{\mathrm{F} 2}=232.6089 \mathrm{MPa}$. Since $\sigma_{\mathrm{F} 2}<\sigma_{\mathrm{FP} 2}$, the calculation satisfies.

According to Eq. (52), the allowed stress on the tooth flank for the wheel gear is $\sigma_{\mathrm{HP} 2}=1543.773 \mathrm{MPa}$. Hence, according to the Eq. (53), it follows that $\sigma_{\mathrm{H} 02}=303.3964$ MPa.

The stress on the tooth flank, according to Eq. (54), is $\sigma_{\mathrm{H} 2}$ $=380.7595 \mathrm{MPa}$. Since $\sigma_{\mathrm{H} 2}<\sigma_{\mathrm{HP} 2}$, the calculation satisfies.

According to the calculation, a planetary transmission with bevel gears was modelled in CAD. The $3 \mathrm{D}$ model is presented in Fig. 9.

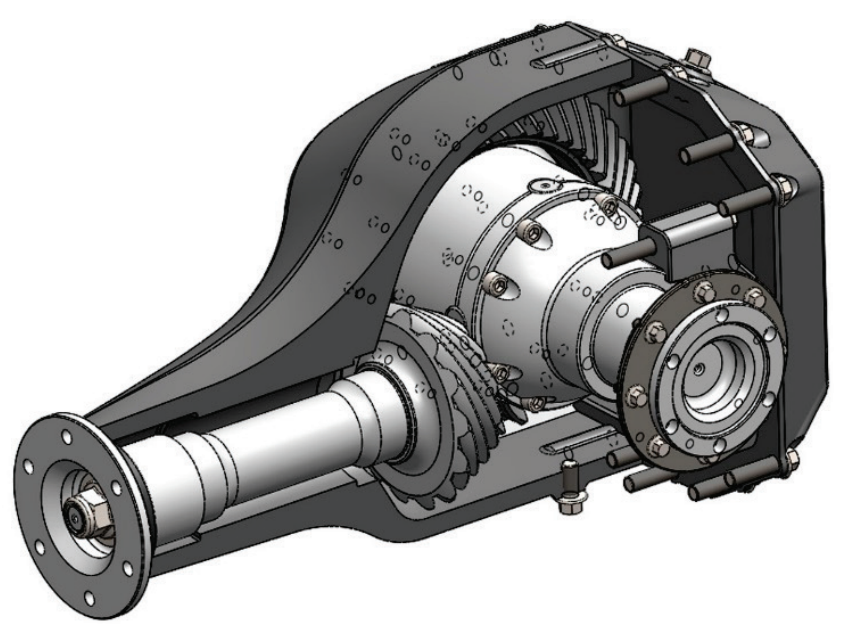

Figure 9 Planetary differential for road vehicles

\section{CONCLUSION}

The differential designed in this paper must enable different rotation speeds on the wheels when they are entering in the bend. Therefore, the most important part of this transmission is planetary transmission, consisting of sun and planetary bevel gears. Bevel gears in comparison with other type of gears have lower loads and usability with more complex geometry and fabrication process. Hence, they 
should be installed in the first degree of the transmission because the smallest torques are there. In this case, they are at the end of the transmission chain and this creates additional problems in the dimensioning process. The momentum of the internal combustion engine first increases in the gearbox, and then it increases in the input gear pair. This ultimately leads to a very high amount of torque that planetary gears have to convey. For this reason, instead of two satellites, a foursatellite construction has been designed to allow the planetary transmission unload.

The load calculation of the tooth root and flank on the planetary bevel gears is based on the stress calculation of the equivalent virtual gears. Some influential factors are taken in value 1 even though their real value is lower. This results with a higher security of the calculation, since the bevel gears have a lower load than the other types of gears. These are the factors such as the load contribution factor, factor of the degree of overlap and the load distribution factor in the root and on the flank tooth. Because of this and the higher amount of torque, there have been a greater number of gear modules in the orientation calculation. Since the dimensions of the differential are limited, a smaller differential is designed with a smaller number of teeth. The stress results were therefore increased, because it could not go for a solution with larger modules or a larger number of teeth. This would result with the dimension increase of the differential. Although the stress results are of higher amounts, the results of the calculation are satisfying because they are lower than the permitted values.

The input gear pair is defined as a hypoid gear pair. This pair has a much quieter pace when transmitting high power and speed. They have a higher degree of overlap and a good grip even in the case of mild improper distribution of the load. The load calculation of the tooth root and the flank on the hypoid gear pair is based on the calculation of the equivalent virtual helical gears. The results are satisfactory and the gears are well dimensioned. Due to the rough calculation of the hypoid pair based on the calculation of virtual gears, it can be concluded that the actual stresses are lower than the calculated. This is because the curved teeth in relation to the helical teeth can carry higher loads and higher speeds with a better degree of overlap.

\section{REFERENCES}

[1] Damjanović, M., Popović, V., \& Simović, S. (2016). Fluctuation of the dynamic load nature in the power transmission train. Tehnički vjesnik - Technical gazette, 23(3), 741-748. https://doi.org/10.17559/TV-20141127151825

[2] Wu, Y.-C. \& Chen, L.-A. (2015). Design of an 8 - speed internal gear hub with a rotary control mechanism for bicycles. Tehnički vjesnik - Technical gazette, 22(4), 865-871. https://doi.org/10.17559/TV-20131225075135

[3] Crolla, D., Foster, E. D., Kobayashi, T., \& Vaughan, N. (2015). Encyclopedia of Automotive Engineering. New Jersey, John Wiley \& Sons.

[4] https://www.myarchive.us/richc/VW_TDI_with_PumpeDuse. pdf
[5] Sabo, I. (2016). Konstruiranje planetarnog prijenosnika sa stožnicima za cestovna vozila. Slavonski Brod, Strojarski fakultet u Slavonskom Brodu.

[6] Kljajin, M., Ivandić, Ž., \& Karakašić, M. (2018). Elementi strojeva-zbirka projektno-konstrukcijskih zadataka. Strojarski fakultet u Slavonskom Brodu.

[7] Oberšmit, E. (1982). Ozubljenja i zupčanici. Zagreb, Sveučilišna naklada Liber.

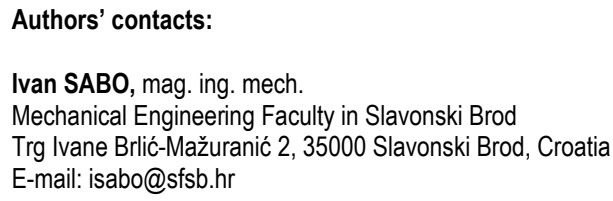

Authors' contacts:

Ivan SABO, mag. ing. mech.

Mechanical Engineering Faculty in Slavonski Brod

Trg Ivane Brlić-Mažuranić 2, 35000 Slavonski Brod, Croatia

E-mail: isabo@sfsb.hr

Milan KLJAJIN, Full professor with tenure

1) Mechanical Engineering Faculty in Slavonski Brod

Trg Ivane Brlić-Mažuranić 2, 35000 Slavonski Brod, Croatia

E-mail: mkljajin@sfsb.hr

2) University North,

Jurja Križanića 31b, 42000 Varaždin, Croatia

E-mail: mkljajin@unin.hr

Mirko KARAKAŠIĆ, Associate professor

Mechanical Engineering Faculty in Slavonski Brod

Trg Ivane Brlić-Mažuranić 2, 35000 Slavonski Brod, Croatia

E-mail: mirko.karakasic@sfsb.hr

Željko IVANDIĆ, Full professor with tenure

Mechanical Engineering Faculty in Slavonski Brod

Trg Ivane Brlić-Mažuranić 2, 35000 Slavonski Brod, Croatia

E-mail: zivandic@sfsb.hr 